\title{
PENGARUH MODEL PEMBELAJARAN RECIPROCAL TEACHING TERHADAP KETERAMPILAN BERBICARA SISWA KELAS V SDN 1 BAREJULAT
}

\author{
Yunita Aryani ${ }^{1)}$, Ida Bagus Kade Gunayasa ${ }^{2)}$, Heri Hadi Saputra ${ }^{3)}$ \\ 1,2,3 PGSD FKIP - Universitas Mataram \\ *Corresponding Author: yunitaaryani732@gmail.com
}

\begin{abstract}
ARTICLE INFO
ABSTRACT

Article history

Received: October 6 $6^{\text {st }}, 2021$

Revised: November $19^{\text {st }}, 2021$

Accepted: December 6 ${ }^{\text {st }}, 2021$

Keywords:

Reciprocal Teaching Learning

Model, Speaking Skills

This study aims to determine the effect of the reciprocal teaching learning model on the speaking skills of fifth graders at SDN 1 Barejulat. The results of this study are expected to be useful theoretically and practically. The type of experimental research used is Quasi Experimental Design in the category of Noneequivalent Control Group Design. Data collection techniques using observation and performance appraisal. The data analysis technique is the prerequisite test 1). Normality test 2). Homogeneity test 3 ). Hypothesis testing using the Anacova test. The results showed that the highest pretest score for the control class $(\mathrm{Vb})$ was 70 , while the lowest score was 45. Then the highest pretest result for the experimental class (Va) was 75 , the lowest was 43 . The highest posttest score for the control class $(\mathrm{Vb})$ was 73 , while the the lowest was 50 . Then the highest posttest result in experimental class (Va) was 83 , the lowest score was 65 . This indicates that there is an effect of the reciprocal teaching learning model on the speaking skills of fifth grade students at SDN 1 Barejulat.
\end{abstract}

\begin{abstract}
ABSTRAK Penelitian ini bertujuan untuk mengetahui pengaruh model pembelajaran reciprocal teaching terhadap keterampilan berbicara siswa kelas V SDN 1 Barejulat. Hasil penelitian ini diharapkan bermanfaat secara teoritis dan praktis. Jenis penelitian eksperimen yang digunakan adalah Quasi Eksperimental Desain katagori Noneequivalent Kontrol Group Design. Teknik pengumpulan data menggunakan observasi dan penilaian unjuk kerja. Teknik analisis data yaitu dengan uji prasyarat 1). Uji normalitas 2). Uji homogenitas 3). Uji Hipotesis menggunkan uji Anakova. Hasil penelitian menunjukkan nilai nilai pretest tertinggi siswa kelas kontrol (Vb) adalah 70, sedangkan nilai terendah 45 . Kemudian hasil tertinggi pretest kelase ksperimen (Va) adalah75, nilai terendah 43. nilai posttest tertinggi siswa kelas kontrol $(\mathrm{Vb})$ adalah 73 , sedangkan nilai terendah 50. Kemudian hasil tertinggi posttestt kelase ksperimen (Va) adalah 83, nilai terendah 65. Hal tersebut menunjukkan bahwa ada pengaruh model pembelajaran reciprocal teaching terhadap keterampilan berbicara siswa kelas V SDN 1 Barejulat.
\end{abstract}

\section{A. PENDAHULUAN}

Pendidikan adalah usaha untuk mempersiapkan peserta didik dalam mengembangkan potensi dirinya melalui kegiatan bimbingan, melatih, serta latihan. Undang-Undang Nomor 20 tahun 2003 tentang Sistem Pendidikan Nasional. Sekolah 
dasar sebagai sekolah awal untuk melanjutkan kejenjang yang lebih tinggi serta suatu saat para siswanya akan tumbuh dewasa dan hidup bermasyarakat, sudah barang tentu harus memberikan perhatian yang lebih, khususnya dalam pembelajaran keterampilan berbicara. Meskipun sulit, keterampilan berbicara sangat penting dikuasai oleh siswa. Mengingat keterampilan berbicara, tes lapangan bahasa yang cenderung kearah keterampilan berbahasa, termasuk keterampilan berbicara.

Keterampilan berbicara dalam mata pelajaran bahasa Indonesia mengarahkan setiap siswa untuk meningkatkan kemampuan berkomunikasi secara lisan dengan baik dan benar dihadapan publik. Keterampilan Berbicara merupakan salah satu komponen penting dalam pembelajaran bahasa Indonesia yang harus dimiliki oleh pendidik dan peserta didik di manapun berada. Terampil berbicara melatih dan menuntut anak didik untuk berkomunikasi dengan siswa lainnya. Supriyadi (2005) menyatakan bahwa sebagian besar siswa khsusnya di Indonesia belum lancar berbicara menggunakan bahasa Indonesia.

Kurangnya keberhasilan siswa siswa dalam keterampilan berbicara disebabkan oleh beberapa hal,diantaranya permasalahan yang sering dihadapi antara lain: (1) siswa belum mampu mengungkapkan ide/gagasan dalam berbicara, (2) siswa kurang percaya diri dan kurang bersemangat dalam belajar berbicara, (3) kurangnya praktik berbicara siswa baik di rumah maupun di sekolah, dan (4) guru dalam melaksanakan kegiatan pembelajaran masih bersifat satu arah (ceramah). Oleh karena itu perlu sebuah model pembelajaran yang tepat untuk mengatasi hal tersebut. Salah satu model pembalajaran yang sesuai untuk diterapkan adalah Reciprocal Teaching.

Reciproal teaching adalah model pembelajaran yang memiliki beberapa keunggulan sebagai berikut. 1). Melatih kemampuan siswa belajar mandiri sehingga kemampuan dalam belajar mandiri dapat ditingkatkan. 2). Melatih siswa untuk menjelaskan kembali materi yang dipelajari kepihak lain. 3). Dalam penerapan pembelajaran ini memfasilitasi siswa dalam mempersentasikan idenya. Dengan demikian kegiatan pertukaran informasi materi terjadi antara sesama siswa dengan empat strategi yang di lakukan dalam kelompok diskusi. Trianto (2011:173) \& Sari (2019) mengatakan bahwa "pengajaran terbalik (Reciprocal Teaching) merupakan pendekatan konstruktif yang berdasarkan pada prinsipprinsip pembuatan/pengajuan pertanyaan". Model pembelajaran reciprocal teaching ini memberikan kesempatan kepada siswa untuk menyampaikan informasi kepada lainnya terakit dengan ringkasan yang dibuatnya.

Sehingga perlu dilakukannya penelitian di SDN 1 Barejulat yang keterampilan berbicara siswa masih terbilang kurang. Sehingga bisa mengetahui ada atau tidaknya pengaruh model pembelajaran reciprocal teaching terhadap keterampilan berbicara siswa kelas V.

\section{B. METODE PENELITIAN}

Penelitian ini adalah salah satu penelitian kuantitatif. Jenis penelitian eksperimen yang digunakan adalah Quasi Eksperimental Desain yaitu Desain ini mempuanyi kelompok kontrol,tetapi tidak dapat berfungsi sepenuhnya untuk mengontrol variablevaribel luar yang mempengaruhi pelaksaan eksperiment (Sugiyono, $2019: 118$ ) katagori Nonequivalent Kontrol Group desain. Dari desain ini dapat diketahui efek dari suatu perlakuan terhadap variabel dependen akan diuji dengan cara membandingkan keadaan 
variabel dependen pada kelompok eksperimen setelah dikenai perlakuan dengan kelompok yang tidak dikenai perlakuan. Populasi merupakan objek/subjek dalam penelitian, sehingga dalam penelitian ini yang ditetapkan sebagai populasi seluruh kelas V SDN 1 Barejulat, yang terdiri dari 2 kelas yang berjumlah 39 peserta didik. Adapun tabel populasi dalam penelitian ini

Menurut Riduwan (2014:70) mengatakan bahwa: "sampel adalah bagian dari populasi”. Sedangkan menurut Sugiyono (2017:118) sampel adalah bagian dari jumlah dan karakteristik yang dimiliki populasi tersebut. Adapun jenis tekanik sampling yang dimaksud dari teknik nonprobability sampling yang digunakan dalam penelitian ini adalah sampling jenuh yaitu teknik penentuan sampel bila semua anggota populasi digunakan sebagai sampel. Metode dalam penelitian ini menggunkan observasi dan penilaian unjuk kerja. Instrument dalam penelitian menggunakan lembar observasi untuk melihat keberhasilan sintaks-sintaks dari model pembelajaran reciprocal teaching, sedangkan penilaian unjuk kerja untukmengukur keterampilan berbicara siswa. Tehnik analsisi data dalam penelitian ini uji normalitas, uji homogenitas dan uji hipotesis.

\section{HASIL DAN PEMBAHASAN}

Dalam hal ini untuk kegiatan belajar mengajar menggunakan model pembelajaran reciprocal teaching diukur dengan keterlaksanaan sintaks-sintaks menggunakan lembar observasi. Peneliti bertindak sebagai pengajar sedangkan guru kelas sebagai observer yang menilai keterlaksanaan sintaks pembelajaran yang diguanakan. Untuk melihat keterlaksaan dari model pembelajaran yang digunkaan sebagai perlakuan untuk kelas eksperimen ditinjau dari lembar observasi keterlaksanaan pembelajaran. Adapun hasil keterlaksanaan pembelajaran dapat dilihat pada tabel berikut.

Tabel 1. Keterlaksanaan Sintaks Pembelajaran

\begin{tabular}{cc}
\hline Pertemuan & Keterlaksanaan \\
\hline 9 & $100 \%$ \\
\hline 2 & $100 \%$
\end{tabular}

Pada tabel diatas dapat diketahui bahwa pada kelas eksperimen peneliti sudah melaksanakan pembelajaran model reciprocal teaching dengan sangat baik.

Hasil keterampilan berbicara pada penelitian ini terdiri dari hasil pretest dan posttest, uji normalitas, uji homogenitas dan uji hipotesis. 
Pretest dan Posttest Hasil Keterampilan berbicara.

Setelah menentukan kriteria penilian unjuk kerja untuk menilai keterampilan berbicara maka selanjutnya dilakukan pretest dan posttest. Nilai rata-rata pretest untuk kelas control, yaitu sebesar 58,78 sedangkan untuk hasil posttest 62,37. Untuk kelas eksperimen nilai rata-rata preteset, yaitu sebesar 58,10 sedangkan untuk nilai rata-rata posttest kelas eksperimen sebesar72,66. Adapaun hasil dari data prestest dan posttest dapat dilihat dari table berikut:

Tabel 2 nilai pretest dan posttes kelas control dan kelas eksperimen Descriptive Statistics

\begin{tabular}{|l|r|r|r|r|r|}
\hline & N & Minimum & Maximum & Mean & Std. Deviation \\
\hline Pretest Kelas Kontrol & 27 & 45 & 70 & 58.78 & 7.261 \\
Postest Kelas Kontrol & 27 & 50 & 73 & 62.37 & 5.651 \\
Pretest Kelas Eksperimen & 29 & 43 & 75 & 58.10 & 7.048 \\
Postest Kelas Eksperimen & 29 & 65 & 83 & 72.66 & 4.378 \\
Valid N (listwise) & 27 & & & & \\
\hline
\end{tabular}

Berdasarkan data di atas dapat di sajikan gambar sebagai berikut:

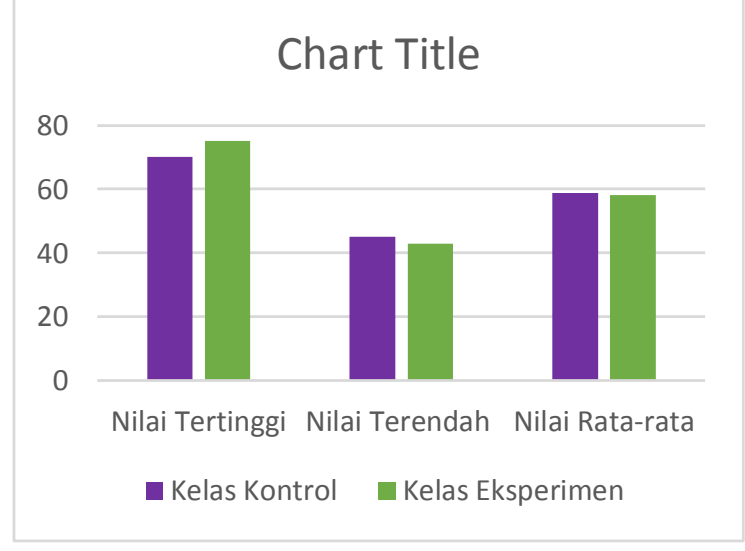

\section{Gambar 1. Hasil Pretest}

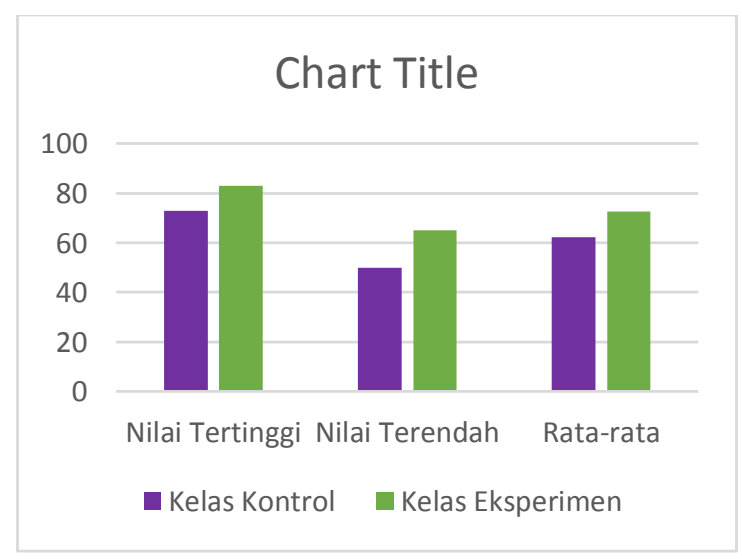

Gambar 2. Hasil Posttest 


\section{Uji Normalitas}

Tabel 3. U.ji Normalitas

\begin{tabular}{|c|c|c|c|c|c|}
\hline \multicolumn{6}{|c|}{ One-Sample Kolmogorov-Smirnov Test } \\
\hline & & $\begin{array}{c}\text { Pretest_kelas } \\
\text { _ kontrol }\end{array}$ & $\begin{array}{l}\text { Pretest_kelas } \\
\text { _eksperimen }\end{array}$ & $\begin{array}{c}\text { Postest_kela } \\
\text { s_kontrol }\end{array}$ & $\begin{array}{c}\text { Postest_kela } \\
\text { s_eksperime } \\
n\end{array}$ \\
\hline$N$ & & 27 & 29 & 27 & 29 \\
\hline Normal Parameters ${ }^{a, b}$ & Mean & 58.78 & 58.10 & 62.37 & 72.66 \\
\hline & Std. Deviation & 7.261 & 7.048 & 5.651 & 4.378 \\
\hline Most Extreme Differences & Absolute & .175 & .123 & .181 & .158 \\
\hline & Positive & .109 & .095 & .181 & .158 \\
\hline & Negative & -.175 & -.123 & -.115 & -.118 \\
\hline Test Statistic & & .175 & .123 & .181 & .158 \\
\hline Asymp. Sig. (2-tailed) & & $.034^{c}$ & $.200^{\mathrm{c}, \mathrm{d}}$ & $.023^{\mathrm{c}}$ & $.062^{\mathrm{c}}$ \\
\hline
\end{tabular}

Berdasarkan tabel diatas, diperoleh nilai kelas kontrol berupa nilai pretest sebesar 0,34>0,05 dapat dikatan data berdistribusi normal, untuk data posttest sebesar $0,23>0,05$ menujukkan data berdistribusi normal. Kelas eksperimen memiliki nilai pretest sebesar 0,200 >0,05 data pretest menunjukkan berdistribusi normal dan data posttest sebesar 0,62>0,05 menunjukan data posttest berdistribusi normal. Jadi kesimpulannya data dari kedua kelas berdistribusi normal.

\section{Uji Homogenitas}

\section{Tabel 4. Uji Homogenitas}

\section{Test of Homogeneity of Variances}

Keterampilan Berbicara

\begin{tabular}{|r|r|r|l|}
\hline Levene Statistic & \multicolumn{1}{|c|}{$\mathrm{df}^{9}$} & \multicolumn{1}{c|}{$\mathrm{df2}$} & \multicolumn{1}{c|}{ Sig. } \\
\hline 4.352 & 3 & 108 & .062 \\
\hline
\end{tabular}

Berdasarkan tabel di atas, terdapat nilai alpha $0.062>0.05$. Jadi dapat disimpulkan bahwa populasi memiliki varian yang homogen atau data berasal dari populasi dengan varian yang sama sehingga dapat dilakukan uji selanjutnya yaitu uji hipotesis.

\section{Uji Hipotesis}

Tabel 5. Uji Hipotesis

\begin{tabular}{|c|c|c|c|c|c|c|}
\hline Source & $\begin{array}{l}\text { Type III Sum } \\
\text { of Squares }\end{array}$ & Df & $\begin{array}{l}\text { Mean } \\
\text { Square }\end{array}$ & $\mathrm{F}$ & Sig. & $\begin{array}{c}\text { Partial Eta } \\
\text { Squared }\end{array}$ \\
\hline $\begin{array}{l}\text { Corrected } \\
\text { Model }\end{array}$ & $1478.991^{a}$ & 1 & 1478.991 & 58.430 & .000 & .520 \\
\hline Intercept & 254920.991 & 1 & 254920.991 & 10071.152 & .000 & .995 \\
\hline Perlakuan & 1478.991 & 1 & 1478.991 & 58.430 & .000 & .520 \\
\hline Error & 1366.848 & 54 & 25.312 & & & \\
\hline Total & 259483.000 & 56 & & & & \\
\hline Corrected Total & 2845.839 & 55 & & & & \\
\hline
\end{tabular}


Berdasarkan tabel diatas, dapat dikatakan bahwa $\mathrm{f}_{\text {hitung }}>\mathrm{F}_{\text {tabel, }}$ yaitu sebesar 58.430 $>4,019$ dan juga memiliki nilai sign $0.000<0,05$. Sehingga dapat ditarik kesimpulan yaitu hipotesis nihil $\left(\mathrm{H}_{0}\right)$ di tolak dan hipotesis alternatef $\left(\mathrm{H}_{\mathrm{a}}\right)$ diterima. Kemudian dari tabel di atas dapat diketahui nilai effect size dengan tehnik partial eta squared adalah sebesar 0,52 yang apabila dipersentasikan yaitu berkisar 52\% pengaruh yang dapat di timbulkan dari variable bebas terhadap variable terikat. Hal ini menunjukkan bahwa "Ada pengaruh yang signifikansi model pembelajaran reciprocal teaching terhadap keterampilan berbicara siswa". Adapun hasil pemberian posttest terhadap kedua kelas .

Penelitian ini bertujuan untuk mengetahui keterampilan berbicara siswa SDN 1 Barejulat dengan menerapkan perlakuan model pembelajaran reciprocal teaching. Pembelajaran reciprocal teaching dilaksanakan dikelas eksperimen sedangkan kelas kontrol mnggunakan model pembelajaran konvensional. Analisis data diawalai dengan uji normalitas untuk mengetahui apakah data berdistribusi dengan normal atau tidak adapun hasil yang didapatkan yaitu, kelas kontrol berupa nilai pretest sebesar 0,34>0,05 dapat dikatan data berdistribusi normal, untuk data posttest sebesar 0,23>0,05 menujukkan data berdistribusi normal. Kelas eksperimen memiliki nilai pretest sebesar 0,200>0,05 data pretest menunjukkan berdistribusi normal dan data posttest sebesar 0,62>0,05 menunjukan data posttest berdistribusi normal. Selanjutnya uji homogenitas dilakukan untuk mengetahui tingkat kesamaan varians kedua data dengan cara membandingkan harga sig pada levene' statistic dengan harga 0,05. Hasil yang didaptkan dalam uji homgenitas yaitu, 0,062>0,05 berarti varians data bersifat homogen.

Pada tahap selanjutnya peneliti memberikan perlakuan dengan menerapkan model pembelajaran reciprocal teaching di kelas eksperimen. Model pembelajaran reciprocal teaching ini dapat menimbulkan aktivitas-aktivitas yang mampu melatih keterampilan berbicara siswa. Pada kegiatan awal siswa yang telah terbagi menjadi beberapa kelompok diminta untuk membaca teks organ gerak manusia dan hewan pada tema satu. Selanjutnya guru mengarah siswa yang bertindak sebagai guru utnuk mengklarifikasikan materi yang belum dipahami kepada teman kelompoknya yang lain (clarifying). Kemudian guru mengarahkan para peserta didik untuk saling memberikan pertanyaan kepada kelompok lain (Question generating). Selanjutnya para peserta didik mengerjakan LKPD yang telah ada dalam buku tema yaitu mengembangkan ide-ide pokok yang telah ditemukan dalam setiap paragraph untuk dijadikan sebuah paragaraf(predicting).

Setelah selesai membuat paragraph guru dalam kelompok mempersilahkan semua angotnya untuk menyampaikan hasil karnyanya didepan kelas (communication). Pemaparan di atas merupakan hasil dari observasi sintaks-sintaks kegiatan pembelajaran menggunakan model pembelajaran Reciprocal Teaching yang di konversikan menurut nilai dari Sudjana 100\% terlaksana dengan baik. Model pembelajaran reciprocal teaching dapat terlaksana dengan baik karena guru melakukan kegiatan pembelajaran sesuai dengan sintaks-sintaks dari model pembelajaran reciprocal teaching tersebut seperti, 1). Megelompokkan siswa dalam diskusi kecil 2). Membuat pertanyaan 3). Menyajikan hasil kerja kelompok 4). Mengklarifikasikan permasalahan 5). Memberikan soal latihan 6). Menyimpulkan materi.

Berbeda halnya dengan kelas kontrol yang diberikan pembelajaran secara konvensional selama 2 kali pertemuan menyebabkan siswa terlihat jenuh dan bosan dalam 
kegiatan pembelajaran. Tujuan pemberian perbedaan perlakuan ini adalah untuk melihat pengaruh model pembelajaran reciprocal teaching (kelas eksperimen) dengan kelas yang menggunakan model pembelajaran yang konvensional (kelas kontrol) terhadap keterampilan beribicara siswa. Pada tahap selanjutnya, data-data hasil yang didapatkan dari keterampilan berbicara siswa yang telah diuji normalitas dan homogenitas akan dilanjutkan dengan uji hipotesis dengan analisis kovarian (Anakova) dengan taraf kepercayaan $5 \%$ diketahui berpengaruh posistif dan signifikan terhadap keetampilan berbicara siswa kelas V SDN 1 Barejulat. Bentuk pengaruh yang postif diketahui dari skor posttest kelas kontrol dan kelas eksperimen yaitu, 62,37 untuk kelas kontrol, sedangkan kelas eksperimen 72,66.

Perbedaan hasil rata-rata keterampilan berbicara antara kedua kelas tersebut dapat dikatan signifikan berdasarakan asumsi statistic karena hasil $\mathrm{f}_{\text {hitung }} 58.430>\mathrm{f}_{\text {tabel }} 4,019$ dengan jumlah sampel 56 peserta didik padataaraf signifikansi 5\%. Selain hasil uji f di atas adapun hasil nilai sig $0.000<0.05$ yang menunjukkan hasil pengaruh dari variable bebas (model pembelajaran reciprocal teaching ) terhadap variable terikat (keterampilan berbicara siswa) dalam penelitian ini berpengaruh postif dan signifikan. Selain mengetahui pengaruh yang didapatkan dari variabel bebas terhadap variabel terikat yang berpengaruh postif dan signifikan, analisis kovariat sebagaimana yang telah dibahas juga dapat menghasilkan nilai effect size. Nilai effect size digunakan untuk mengetahui seberapa besar pengaruh yang diberikan dari model pembelajaran reciprocal teaching terhadap keterampilan berbicara. Untuk mengetahui nilai effect size melalui Teknik partial eta squared dengan perolehan nilai sebesar 0,52 atau sipersentasikan sebesar 52\%, maka dapat dikatan model pembelajaran reciprocal teaching memiliki pengaruh sebesar 52\% terhadap keterampilan berbicara siswa

Aktivitas-aktivitas yang telah dilakukan selama proses pembelajaran dengan model pembelajaran reciprocal teaching dapat membentuk pembelajaran yang lebih aktif dan memberikan kesempatan pada siswa utnuk menemukan serta memverifikasi informasi yang telah diterima (Suprijono, 2012; Akhir, 2017). Informasi didapatkan darikegiatan membaca materi sementara untuk proses memverifikasi didapatkan dari saling bertanya yang bersifat komunikatif kepada teman maupun guru serta mengkomunikasikan hasil temuannya didepan kelas. Proses mengkomunikasikan inilah yang menjadi inti dari keetrampilan berbicara siswa, dimana siswa diharapkan mampu mengkomunikasinya hasil temuannya dengan tepat agar teman-temannya yang lain mengerti dan paham dengan apa yang telah disampaikan. Model pembelajaran sangat baik digunakan untuk melatih dan meningkatkan keterampilan berbicara siswa aktif dan tidak diam sekali selama proses pembelajaran berlangsung. Pada pembelajaran Bahasa Indonesia memiliki 4 keterampilan, salah satunya adalah keterampilan berbicara yang khusunya dituntut untuk konsentrasi dan fokus agar dapat memperoleh, dan mengolah informasi yang didapatkan dari belajar mandiri.

Berdasarkan pemaparan diatas dan sejalan dengan yang di kemukakan oleh Shoimin, (2013) \& Rosenshine \& Meister (1994) bahwa model pembelajaran reciprocal teaching dapat menumbuhkan bakat siswa terutama dalam berbicara dan mengembangkan sikap. Maka dari itu hipotesis alternatif (Ha) yang berbunyi Ada pengaruh yang signifikansi 
model pembelajaran reciprocal teaching terhadap keterampilan berbicara siswa kelas $\mathrm{V}$ SDN 1 Barejulat dinyatakan diterima.

\section{PENUTUP}

\section{Simpulan}

Berdasarkan hasil penelitian, analysis data dan pembahasan maka, dapat ditarik kesimpulan bahwa ada pengaruh model pembelajaran reciprocal teaching terhadap keterampilan berbicara siswa kelas V SDN 1 Barejulat tahun ajaran 2021/2022. Hal ini ditunjuukan dari hasil uji hipotesis dengan uji f dengan anailisis kovarian yaitu dengan nilai bahwa $\mathrm{f}_{\text {hitung }}>\mathrm{F}_{\text {tabel, }}$ yaitu sebesar $58.430>4,019$ dan juga memiliki nilai sign 0.000 $<0,05$. Sehingga dapat ditarik kesimpulan yaitu hipotesis nihil $\left(\mathrm{H}_{0}\right)$ di tolak dan hipotesis alternatef $\left(\mathrm{H}_{\mathrm{a}}\right)$ diterima. dapat diketahui nilai effect size dengan tehnik partial eta squared adalah sebesar 0,52 yang apabila dipersentasikan yaitu berkisar $52 \%$ pengaruh yang dapat di timbulkan dari variable bebas terhadap variable terikat.

\section{Saran}

Berdasarkan hasil penelitian dan pembahasan, maka saran vang diberikan adalah sebagai berikut. (1) bagi Kepala Sekolah Model pembelajaran reciprocal teaching ini menuntut pengetahuan siswa untuk berani mengungkapkan pendapatnya maka diharapkan kepala sekolah agar turut mendukung pembelajaran yang aktif, bermakna, dan menyediakan fasilitas yang mendukung terlaksananya proses pembelajaran; (2) bagi Guru Guru diharapkan dapat melanjutkan penggunaan model reciprocal teaching menjadi salah satu alternatif pembelajaran yang dapat diterapkan oleh guru dalam rangka meningkatkan keterampilan berbicara siswa; dan (3) bagi Siswa Dengan menggunakan model reciprocal teaching proses belajar menjadi lebih menarik, sehingga materi yang dipelajari dapat dipahami dengan baik, sehingga mampu meningkatkan keterampilan berbicara siswa; dan (4) bagi Penelítian Lain Penelitian selanjutnya diharapkan untuk memperluas lingkup penelitian yang telah dilaksanakan ini sehingga adanya variasi dan kebaharuan data

\section{DAFTAR PUSTAKA}

Akhir, M. (2017). Penerapan strategi belajar reciprocal teaching terhadap kemampuan membaca pada siswa SD. Indonesian Journal of Primary Education, 1(2), 30-38.

Arikunto, Suharsimi. (2013). Prosedur Penelitian Suatu Pendekatan Praktik. Jakarta: Rineka Cipta

Rosenshine, B., \& Meister, C. (1994). Reciprocal teaching: A review of the research. Review of educational research, 64(4), 479-530.

Riduwan. (2014). Metode \& Teknik Penyusunan Proposal Penelitian. Bandung: Alfabeta

Sari, Y. I., Putra, I. K. A., \& Suniasih, N. W. (2019). Pengaruh Model Reciprocal Teaching terhadap Keterampilan Menulis Bahasa Indonesia. Journal of Education Technology, 3(2), 58-64.

Shoimin, Aris. (2014). 68 Model Pembelajaran INOVATIF dalam Kurikulum 2013. Yogyakarta: AR-RUZZ MEDIA.

Sugiyono. (2019) . Metode Penelitian Pendidikan (pendekatan kuantitatif, kualitatif, dan 
$R \& D)$. Bandung: Alvabeta.

Suprijono, Agus. (2012). Cooperatif Learning. Yogyakarta: Pustaka Pelajar

Supriyadi , dkk. (2005). Pendidikan Bahasa Indonesia2. Jakarta: Depdikbud

Trianto. (2011). Model-Model Pemnelajaran Inovatif Beriorentasi Konstruktivistik (Konsep,

Landasan, Teoritis-Praktis dan Implementasinya). Jakarta: Prestasi Pustaka

Undang Undang Nomor 20 Tahun 2013 tentang Sistem Pendidikan Nasional 